\title{
Sperm as an indicator of reproductive risk among petroleum refinery workers
}

\author{
M J ROSENBERG, ' A J WYROBEK, ${ }^{2}$ JENNIFER RATCLIFFE, ' L A GORDON, ${ }^{2}$ \\ G WATCHMAKER, ${ }^{2}$ S H FOX,,${ }^{1}$ D H MOORE II, ${ }^{2}$ AND R W HORNUNG'
}

From the National Institute for Occupational Safety and Health, ' Centers for Disease Control, Cincinnati, Ohio 45226, and Biomedical Sciences Division, ${ }^{2}$ Lawrence Livermore National Laboratory, Livermore, California 94550, USA

ABSTRACT A questionnaire study of men in a wastewater treatment plant of a petroleum refinery showed twice the rate of fetal loss in the period during employment in the plant compared with the periods before and after. Questions regarding the interpretation of that study and continuing concern about reproductive risk prompted us to perform a cross sectional evaluation of sperm concentration and morphology. After adjustment for an abstinence period, the mean sperm concentration of the 74 unexposed men did not differ significantly from that of the 34 exposed men (79.9 million $\left./ \mathrm{cm}^{3} v 68.2 \mathrm{million} / \mathrm{cm}^{3}, \mathrm{p}_{(1)}=0.16\right)$. The two groups also had a similar proportion of sperm with abnormal morphology $\left(49.1 \% v 44.5 \%, \mathrm{p}_{(1)}=0.94\right)$. This lack of association remained when degree of exposure, age, use of alcohol and marijuana, past illness or fever, use of baths or sauna, and history of urological problems were considered. These results are most consistent with the absence of sperm mediated reproductive problems.

Male exposures to physical and chemical toxins may increase the chance of spontaneous abortion independently of female factors. ${ }^{2}$ Separate lines of evidence link abnormal human sperm morphology and decreased concentration to infertility, ${ }^{34}$ and, with less certainty, to increased frequency of spontaneous fetal loss. ${ }^{5-8}$ Research from animals and man suggests that sperm concentration and morphology are sensitive indicators of sperm production. ${ }^{910}$

Perception of an excessive rate of spontaneous abortions among the wives of workers in the wastewater treatment plant of a large refinery led to a questionnaire survey of the workers' spouses." The study found that for unexposed wives, the rate of fetal loss was significantly higher when the husband worked in the treatment plant near the time of conception $(17.0 \%)$ than when he did not $(8.2 \%)$. Interpretation of this study, however, was limited by methodological problems and by the inability to distinguish a male mediated mutagenic (preconception) effect from an embryotoxic (postconception) effect. Because of the continuing concern about the reproductive risk arising from working in the plant, we conducted a cross sectional evaluation of sperm concentration and the proportion of sperm with

Received 5 December 1983

Accepted 19 March 1984 abnormal morphology in exposed workers and two groups of unexposed men.

\section{Methods}

DESCRIPTION OF REFINERY

The plant refines crude petroleum into various products, including motor fuels, lubricants, and specialty products such as asphalt. About 500000 barrels of crude oil are processed daily and the plant employs about 2050 workers. The wastewater treatment plant purifies water contaminated mainly by organic compounds. This plant, in operation since 1976, consists of flotation tanks for removing oil residues, settling tanks for separating solids, aeration tanks for degrading biological materials, and a filter for concentrating sludge.

Refinery workers are divided into two groups, mechanical and process. Mechanical workers include craftsmen such as pipefitters, electricians, machinists, and other technicians who work full time in the refinery yard. Process workers spend some of their time in control rooms and other buildings as well as in the refinery proper.

STUDY PARTICIPATION

Men were considered exposed if they had worked in 
Table 1 Study participation

\begin{tabular}{|c|c|c|c|c|}
\hline & No selected for participation & No ineligible* & No participating & $\%$ (of eligible) \\
\hline $\begin{array}{l}\text { Exposed (to treatr } \\
\text { Process } \\
\text { Mechanical } \\
\text { Unexposed: } \dagger\end{array}$ & $\begin{array}{l}36 \\
32\end{array}$ & $\begin{array}{l}3 \\
3\end{array}$ & $\left.\begin{array}{l}21 \\
21\end{array}\right\}$ & $68 \%$ \\
\hline $\begin{array}{l}\text { Refinery } \\
\text { Process } \\
\text { Mechanical } \\
\text { Administrative }\end{array}$ & $\begin{array}{r}50 \\
50 \\
100\end{array}$ & $\begin{array}{r}10 \\
8 \\
15\end{array}$ & $\left.\begin{array}{l}17 \\
21 \\
36\end{array}\right\}$ & $44 \%$ \\
\hline
\end{tabular}

*Due to vasectomy or vacation at time of study.

tSelected randomly from company records.

the wastewater treatment plant during the six months before this study. The overall participation among this group was $68 \%$ (table 1). Each man's time was weighted by job classification according to the proportion of time spent in the yard (supervisors, 0.4 ; assistant supervisors, 0.6 ; mechanical and process workers, $1 \cdot 0$ ).

Unexposed workers were randomly selected from 100 men working in other parts of the refinery and a second group of 100 administrative workers who did not work in the refinery proper. Overall participation for the unexposed men was $44 \%$ (table 1 ).

QUESTIONNAIRE, PHYSICAL EXAMINATION, AND SPECIMEN COLLECTION

Each participant completed a questionnaire and

Table 2 Characteristics of exposed and unexposed refinery workers

\begin{tabular}{|c|c|c|}
\hline Characteristic & $\begin{array}{l}\text { Exposed } \\
(n=42)^{* *}\end{array}$ & $\begin{array}{l}\text { Unexposed } \\
(n=74)^{* *}\end{array}$ \\
\hline $\begin{array}{l}\text { Age (y) (mean } \pm \text { SD) } \\
\text { Sexual abstinence (days) (mean } \pm \text { SD) } \\
\text { Abnormal physical examination* } \\
\text { Other occupational exposures }(\%) \dagger \\
\text { Abnormal medical history }(\%) \ddagger \\
\text { Fever }(\%) \S \\
\text { Use of prescribed drugs }(\%) / / \\
\text { Use of sauna or hot baths }(\%) \nsubseteq \uparrow\end{array}$ & $\begin{array}{r}31 \cdot 6 \pm 5 \cdot 3 \\
2 \cdot 9 \pm 1 \cdot 3 \\
9 \cdot 5 \\
25 \cdot 7 \\
25 \cdot 7 \\
8 \cdot 1 \\
12 \cdot 1 \\
21 \cdot 6\end{array}$ & $\begin{aligned} & 34 \cdot 9 \pm 10 \cdot 4 \\
& 3 \cdot 6 \pm 2.9 \\
& 16 \cdot 2 \\
& 47 \cdot 6 \\
& 16 \cdot 7 \\
& 9 \cdot 5 \\
& 14 \cdot 3 \\
& 33 \cdot 3\end{aligned}$ \\
\hline $\begin{array}{l}\text { Use of cigarettes (packs/day, \%): } \\
\text { None } \\
<1 \\
1 \\
2 \\
\geqslant 3\end{array}$ & $\begin{array}{r}78 \cdot 4 \\
6 \cdot 8 \\
9 \cdot 5 \\
5 \cdot 4 \\
0 \cdot 0\end{array}$ & $\begin{array}{r}61 \cdot 9 \\
7 \cdot 1 \\
21 \cdot 4 \\
7 \cdot 1 \\
2 \cdot 4\end{array}$ \\
\hline $\begin{array}{l}\text { Marijuana use (or declined to } \\
\text { answer, \%) }\end{array}$ & $9 \cdot 5$ & $19 \cdot 1$ \\
\hline $\begin{array}{l}\text { Use of alcohol (drinks/day, \%): } \\
\text { None } \\
<1 \\
1-3 \\
>3\end{array}$ & $\begin{array}{l}18 \cdot 9 \\
14 \cdot 9 \\
44 \cdot 6 \\
21 \cdot 6\end{array}$ & $\begin{array}{l}21 \cdot 4 \\
21 \cdot 4 \\
23 \cdot 8 \\
33 \cdot 3\end{array}$ \\
\hline
\end{tabular}

*Presence of varicocele, hydrococle, hernia, or single testicle. tTo solvents, formaldehyde, coal, dyes, or lead within past year. ¥History of hepatitis, urinary tract infection, mononucleosis, varicocole, or diabetes mellitus.

\$At least $101^{\circ} \mathrm{F}$ in past three months.

//Antibiotics, propranolol, or cimetidine, in past three months.

IITWeekly or more frequently.

**Excludes missing responses except where noted. underwent a physical examination concentrating on the urogenital tract (table 2). The physical examination which was conducted with no knowledge of the subject's exposure, was considered abnormal if it showed a varicocele, hydrocele, inguinal or femoral hernia, or a single testicle. Specimens of semen were collected by masturbation into plastic urine containers after at least two days of sexual abstinence and brought to an on site laboratory within three hours of collection.

Each sample was gently mixed with a pipette, and thin air dried smears were made for later analysis of sperm morphology. The remainder of the sample was frozen for later determination of sperm concentration; some samples were not adequate for both determinations.

\section{ANALYSIS OF CONCENTRATION AND MORPHOLOGY}

Frozen specimens were thawed and their volume was determined by graduated pipette. The samples were mixed and then diluted 1:10 using phosphate buffered saline with $3 \%$ formalin. The sperm concentration was averaged from eight haemocytometic readings for each sample. To analyse the morphology the air dried smears were stained with Papanicolaou's stain. For each sample, 500 sperm were evaluated according to ten categories of shape described by Wyrobek et al. ${ }^{12}$ Slides were scored in random order. For quality control, slides selected at random from a separate standardised set were coded and evaluated, both before each scoring session and after every fifth field sample.

\section{STATISTICAL ANALYSIS}

For concentration among unexposed subjects, the square root transformation gave the most satisfactory approximation to a normal distribution ${ }^{13}$ and was used for the analysis of sperm concentration. Sperm morphology scores among the unexposed men were normally distributed.

The means of the exposed and unexposed groups were compared using a one sided $t$ test, with equality 
Table 3 Sperm concentration and proportion of sperm with abnormal morphology in refinery workers

\begin{tabular}{|c|c|c|c|c|c|c|}
\hline \multirow[t]{2}{*}{ Exposure group } & \multicolumn{3}{|c|}{ Sperm concentration * } & \multicolumn{3}{|c|}{ Sperm morphology $\dagger$} \\
\hline & No of subjects $\ddagger$ & Mean & $\begin{array}{l}\text { Standard } \\
\text { deviation }\end{array}$ & No of subjects $\ddagger$ & Mean & $\begin{array}{l}\text { Standard } \\
\text { deviation }\end{array}$ \\
\hline $\begin{array}{l}\text { Exposed: } \\
\quad \text { Process } \\
\text { Mechanical } \\
\text { All subjects } \\
\text { Adjusted mean, all subjects } \$ \\
\text { Unexposed: }\end{array}$ & $\begin{array}{l}21 \\
21 \\
42\end{array}$ & $\begin{array}{l}65.4 \\
82.6 \\
74 \cdot 0 \\
66.9\end{array}$ & $\begin{array}{l}60-6 \\
65 \cdot 8 \\
63 \cdot 1\end{array}$ & $\begin{array}{l}19 \\
20 \\
39\end{array}$ & $\begin{array}{l}40 \cdot 9 \\
47 \cdot 9 \\
44 \cdot 5 \\
44 \cdot 0\end{array}$ & $\begin{array}{r}9.0 \\
15.9 \\
13.3\end{array}$ \\
\hline $\begin{array}{l}\quad \text { Refinery } \\
\quad \text { Process } \\
\quad \text { Mechanical } \\
\text { Administrative } \\
\text { All subjects } \\
\text { Adjusted mean, all subjects } \S \\
\text { Significance }\left(\mathrm{p}_{(1)} \text { of adjusted }\right.\end{array}$ & $\begin{array}{l}16 \\
21 \\
34 \\
71\end{array}$ & $\begin{array}{r}97.9 \\
103.5 \\
97.3 \\
99.2 \\
80.8\end{array}$ & $\begin{array}{l}78.4 \\
88.8 \\
88.6 \\
85.4\end{array}$ & $\begin{array}{l}16 \\
21 \\
36 \\
73\end{array}$ & $\begin{array}{l}51 \cdot 6 \\
47 \cdot 3 \\
49 \cdot 2 \\
49 \cdot 1 \\
48 \cdot 8\end{array}$ & $\begin{array}{l}11.6 \\
17.8 \\
15.4 \\
15.6\end{array}$ \\
\hline $\begin{array}{l}\text { means, exposed } v \text { unexposed } \\
\text { subjects) }\end{array}$ & & $0 \cdot 16$ & & & 0.95 & \\
\hline
\end{tabular}

*Number of sperm per millilitre of ejaculate, in millions; square root transformation used for statistical comparison.

†Proportion of abnormally shaped sperm based on scoring 500 sperm per sample by the criteria of Wyrobek et a!. ${ }^{12}$

$\ddagger$ Number of samples may differ for concentration and morphology because some samples were not adequate for both determinations (low volume or very low counts).

\$Adjusted for abstinence period.

of variance evaluated by the folded $f$ statistic. ${ }^{14}$ For comparisons within groups, analysis of covariance was used. ${ }^{14}$ The presence of factors associated with concentration or morphology and of exposure that might have distorted comparisons using the $t$ test was tested for with analysis of covariance and a stepwise regression model. ${ }^{14}$

\section{Results}

\section{CHARACTERISTICS OF THE COHORTS}

The exposed and unexposed groups are generally similar for those characteristics determined by questionnaire and physical examination (table 2). The major differences between the two groups were mean period of sexual abstinence, the proportion with other occupational exposures during the past year, and the proportion of non-smokers. The possibility that these, or other characteristics in table 2 , distorted the comparison of sperm was tested using a multivariable model (see below).

\section{SPERM CONCENTRATION}

Among the unexposed subjects, those refinery workers classified as mechanical did not differ from the process or administrative workers with respect to sperm concentration $\left(\mathrm{p}_{(2)}=0 \cdot 99\right)$. All the unexposed subjects were therefore pooled to form a single group of 71 . The period of sexual abstinence was the only factor among those shown in table 2 that differed between the exposed and unexposed groups and was related to sperm concentration $\left(p_{(1)}\right.$
$=0.01)$. After adjustment by analysis of covariance, the mean concentrations of the exposed and unexposed cohorts did not differ significantly (66.9 \pm 10.5 and $80.8 \pm 8.6$ million $/ \mathrm{cm}^{3}$, mean \pm standard error; $\mathrm{p}_{(1)}=0 \cdot 16$, table 3 ).

Multiple regression was used to examine the possibility that a trend of decreasing sperm concentration might be related to the number of hours worked in the previous six months. For this analysis, only the 42 exposed men were included. The number of hours worked was not significantly associated with concentration after adjusting for abstinence period $\left(p_{(1)}=0 \cdot 16\right)$. These results did not change when other hours worked in the three months before the study were considered.

\section{SPERM MORPHOLOGY}

Among the unexposed subjects, morphology did not differ according to job classification $\left(\mathrm{p}_{(2)}=0.70\right)$, and unexposed subjects were combined to form a single group of 73 (table 3 ). The mean proportion of abnormally shaped sperm was similar in both unexposed and exposed groups $\left(49.1 \%\right.$ and $44.5 \%, \mathrm{p}_{(1)}$ $=0.94$ ) and was not altered by adjustment for abstinence or other factors shown in table 2.

Among the 39 exposed men for whom sperm morphology data were available, there was no significant linear relationship between the proportion of abnormally shaped sperm formed and the hours worked in the wastewater plant $\left(p_{(1)}=0.08\right)$. Neither period of abstinence, nor any of the other factors shown in table 2 , were significantly correlated. 


\section{Discussion}

These data indicate no significant differences in sperm concentration or in proportion of abnormal morphology according to whether men work in the wastewater treatment plant, elsewhere in the refinery, or in administrative positions. These results did not change when the potentially distorting effects of age, cigarette smoking, alcohol, use of marijuana, or other factors were considered. In addition, there was no evidence to suggest a relation between the number of hours worked and decreasing sperm concentration or increasing proportion of abnormally shaped sperm.

The degree of reproductive risk that may be inferred from changes in sperm involves several links. Firstly, recent human studies have shown that male exposures affect the probability of fetal loss independent of female factors. ${ }^{12}$ This confirms work in various animals which shows that paternal exposures may adversely affect reproduction when there is no maternal exposure. ${ }^{15}$ Secondly, decreased sperm concentration and increased proportion of abnormally shaped sperm are associated with infertility ${ }^{34}$ and in a less certain way with increased rates of fetal loss. ${ }^{5-816}$ Finally, a growing body of research, based on human and animal work, indicates that sperm concentration and morphology are sensitive indicators of spermatogenic function. ${ }^{910}$

The number of subjects studied may limit the ability to detect small changes even if an underlying difference is really present. Our sample of 42 exposed and 73 unexposed men was sufficient to have had an $80 \%$ chance of detecting a $7.3 \%$ or greater increase in abnormally shaped sperm as compared with the unexposed mean (adjusted for abstinence period) of $48.8 \%$ (D H Moore, personal communication). For concentration, our sample size allowed an $80 \%$ chance to detect a decrease of at least $39 \%$ compared with the adjusted mean for the unexposed group of $80.8 \mathrm{million} / \mathrm{cm}^{3}$.

Studies with incomplete participation may be biased if systematic differences exist between the participants and non-participants. The nonparticipants in this study were older than the participants (mean ages 37.8 and 33.7 years, respectively) but neither age nor any other characteristics of the participants appreciably altered the findings. A second cause of bias toward the lack of association comes from the possibility that men with suspected reproductive problems from the wastewater treatment plant may have been less likely to participate than men with suspected problems in the unexposed group. Nevertheless, strong employee interest in the treatment plant was reflected in substantially better participation rates among this group than among the non-exposed workers. The likely effect of such bias would therefore be to show an association rather than its lack. These sources of bias are thus unlikely explanations of our results.

A previous study of spontaneous abortion, interpreted by its authors as demonstrating the presence of excess risk, ${ }^{11}$ is difficult to compare directly with our study. Firstly, our study is cross sectional, whereas the earlier study evaluated the pregnancies of wives of workers in the wastewater treatment plant between 1936 and about two years before our work was performed. Apart from methodological differences that preclude direct comparison, numerous environmental changes in the wastewater treatment plant had been made since the previous study (FS Venable, personal communication), so that the working environment at the time of our study differed. The previous study also relied on women's memory of the outcome of pregnancy. Although each reported fetal loss was carefully documented by researchers and found to agree closely with medical records, the contribution of forgotten episodes of fetal loss could not be evaluated. That study found a rate of fetal loss among pregnancies occurring between 1936 and 1981, when men did not work in the plant, of $8.2 \%$. This rate is about half that expected. ${ }^{17}$ The rate between 1976 and 1981, when men worked in the plant, was $17.0 \%$. This discrepancy is consistent with recall bias which may sub-ç stantially explain the study's results. Concern also arises from the small number of spontaneous abortions which the study considered.

If the results of the previous study are accepted, however, two mechanisms might explain the apparent increase. The first, favoured by the authors of the previous study, is that a short lived effect changed the genetic composition of sperm of the exposed workers, leading to fertilisation by genetically abnormal sperm and subsequent fetal loss. Our findings suggest that there is no sperm mediated problem at present but do not indicate whether a problem might have occurred in the past. The second explanation is that an embryotoxic factor or substance, perhaps transmitted through the skin, by contact with clothes, or by semen, may have led to fetal loss even after fertilisation by normal sperm. Our study did not address the possible embryotoxic effect.

This evaluation indicates that spermatogenic impairment was probably not present at the wastewater treatment plant at the time of our study. The findings might be re-evaluated by another cross sectional study with a larger group of men, perhaps also at another refinery. Alternatively, a longitudinal evaluation of the semen of men who begin work in the wastewater treatment plant could be performed. 
The question of excessive spontaneous abortions could be addressed by monitoring pregnancy outcomes in wives of refinery workers.

We are grateful for the clerical help of P DuPont, B Vehr, B Walpole, and C Battaglia, and editing by $J$ Cherniak and A Crochet. We also thank Drs J Higgins, B Gledhill, M Mendelsohn, F Hatch, and C Meyer for their helpful comments.

A portion of this project was performed under Family Health International Sponsorship.

Requests for reprints to: Dr Michael J Rosenberg, Family Health International, Research Triangle Park, NC 27709, USA.

\section{References}

' Hemminki K, Kyyronen P, Neimi M-L, et al. Spontaneous abortions in an industrialized community in Finland. Am J Public Health 1983;73:32-7.

${ }^{2}$ Kharrazi M, Potashnik G, Goldsmith JR. Reproductive effects of dibromochloropropane. Israel J Med Sci 1980;16:403-6.

${ }^{3}$ Spira A, Mayaux M-J, Schwartz D, Jouannet P, Czyglick F, David G. Quelques aspects methodologiques d'une enquete retrospective comparant 484 hommes feconds et 2768 hommes infeconds. Rev Epidemiol Sante Publique 1980;28:13-20.

4 Aitken RJ, Best FSM, Richardson DW, et al. An analysis of sperm function in cases of unexplained infertility: conventional criteria, movement characteristics, and fertilizing capacity. Fert Steril 1982;38:212-21.

${ }^{5}$ Czeizel C, Hancsok M, Viczian M. Examination of the semen of husbands of habitually aborting women. Orvosi Hetilap 1967; 108:1591-5.

- Joel CA. New etiologic aspects of habitual abortion and infertil- ity, with special reference to the male factor. Fert Steril 1966;17:374-80.

7 Joel CA. The role of spermatozoa in habitual abortion. Fertil Steril 1955;6:459-64.

${ }^{8}$ Furuhjelm M, Jonson B, Lagergren C-G. The quality of human semen in spontaneous abortion. Int $J$ Fertil 1962; 7:17-21.

${ }^{9}$ Wyrobek AJ, Gordon LA, Burkhart JG, et al. An evaluation of the mouse sperm morphology test and other sperm tests in nonhuman mammals: a report of the US Environmental Protection Agency Gene-Tox Program. Mutat Res 1983;115:172.

${ }^{10}$ Wyrobek AJ, Gordon LA, Burkhart JC, et al. An evaluation of human sperm as indicators of chemically induced alterations of spermatogenic function: a report of the US Environmental Protection Agency Gene-Tox Program. Mutat Res 1983;115:73-148.

"Morgan RW, Kheifets L, Obrinsky DL, Whorton MD, Foliart DE. Fetal loss and work in a wastewater treatment plant. Am J Public Health 1984; 74:499-501.

12 Wyrobek AJ, Gordon LA, Watchmaker G, Moore DH. Human sperm morphology testing: description of reliable method and its statistical power. Banbury report 13. Indicators of genotoxic exposure. New York: Cold Springs Harbor Laboratory, 1982:527-41.

${ }^{13}$ Gold HJ. The KSLTEST procedure. In: Reinhardt PS, ed. SAS supplemental library user's guide. Cary, NC: SAS Institute, 1980:75-7.

${ }^{14}$ Helwig JT, Council KA, eds. SAS user's guide: statistics. Cary, NC: SAS Institute, 1982:101-11, 139-99, 245-55.

is Soyka LF, Joffe JM. Male-mediated drug effect on offspring. In: Schwartz RH, Yaffe SJ, eds. Drug and chemical risks to the fetus and newborn. New York: Alan Liss, 1980:49-66.

${ }^{16}$ Homonnai ZT, Pax GF, Weiss JN, David MP. Relation between semen quality and fate of pregnancy: retrospective study on 534 pregnancies. Int J Androl 1980;3:547-84.

1 Harlap S, Shiono PH, Ramcharan S. A life table of spontaneous abortions and the effects of age, parity, and other variables. In: Porter IH, Hook EB, eds. Human embryonic and fetal death. New York: Academic Press, 1980:145-8. 